\title{
Dying young: Excess morbidity and mortality in individuals with severe mental illness and what we should be doing about it
}

\author{
Darya Kurowecki, BSc, $\mathrm{MA}^{1}$, Justin Godbout, $\mathrm{BSc}^{1}$
}

${ }^{1}$ Faculty of Medicine, University of Ottawa

"We talk about people with mental illness, and people with diabetes, and smokers and the obese, and so on and so on. We're talking about the same people - just with different labels." - Health care professional [1, p. 6]

Severe mental illness (SMI) most commonly refers to mental disorders with a psychotic component and significantly reduced functioning despite the presence of inherent differences in risk factors, etiologies, and treatments [1]. The most common disorders that fall under this term include schizophrenia and bipolar disorder [1]. Over a decade of research into the morbidity and mortality of individuals with SMI has consistently revealed mortality rates two to three times higher and a life expectancy of 25-30 years shorter compared to the general population [1-4]. Contrary to popular belief, the main causes of early death are not drug overdose or suicide, but rather, preventable illnesses such as cardiovascular disease, diabetes, and HIV/AIDS [1,3,5-7]. Incidence of other preventable conditions, such as obesity and respiratory disease, is also much higher among patients with SMI, and when present, is associated with a more severe course of mental illness and a reduced quality of life $[3,8]$. Such findings bring significant questions: what is the cause of this disparity in mortality/ morbidity? What can health care professionals do to help reduce this gap?

A recent report by the Early Onset IIIness and Mortality Working Group [1] outlines several factors that may contribute to poor physical health of people with SMI. Some factors, such as those related to the mental illness itself (e.g., cognitive impairment, a lack of communication skills, medication side-effects) and socioeconomic status (e.g., poverty, poor education) may be less amenable to modification, but should nevertheless be a target for action. Other contributing factors include behaviour and lifestyle (e.g., physical inactivity, obesity, tobacco smoking), and poor preventative medical care (e.g., disparity in quality of medical care), both of which are more easily modifiable with the assistance of medical care practitioners. Here we will summarize the factors responsible for poor physical health in SMI, specifically focusing on the mental illness itself, socioeconomic status, behaviour and lifestyle, health care system barriers, and insufficient preventative medical care. We will then propose future directions and ways in which medical students and current medical professionals can help reduce this gap.
Factors Related to the mental illness itself

"Sometimes depression gets in the way. I have to work my way through the maze of it. If I'm not feeling okay emotionally, it's hard to care about the physical." - Patient [1, p 13].

There is significant evidence that the presence of mental illness may impact individuals' help-seeking behaviour, thus contributing to excess mortality and increased physical health problems [3]. For example, patients with SMI make fewer medical visits than the general population [9], are more functionally impaired [10], and are less likely to spontaneously report physical symptoms or seek adequate physical care [11]. This lack of helpseeking behaviour may be due to the symptoms of the SMI like social isolation and suspicion [11,12], a general lack of awareness of physical problems because of cognitive deficits [12], reduced pain sensitivity from psychotropic medication [11,12], and/or difficulty in communicating physical needs $[12,13]$. The side effects of medications used to treat SMI in particular may also not only hinder help-seeking behaviour, but also may directly contribute to obesity and cardiovascular disease [14]. For example, while treating depression may alleviate apathy and lack of motivation, thereby enhancing patients' ability to seek medical care for physical illnesses, psychotropic medications for schizophrenia and bipolar disorder not only directly increase the risk of physical side effects, but also increase apathy and further contribute to decreased help-seeking behaviour [14].

Physicians must therefore be aware of the potential impact of mental illness and medications on help-seeking behaviour and physical health of patients with SMI, and respond accordingly. This act by physicians is especially important since findings show both primary and mental health care practitioners (including psychiatrists) as being less likely to inquire about their patients with SMI. For example, the smoking status of patients with SMI may not even be asked, thereby suggesting that these patients are treated differently as a result of their mental illness. In addition, there is evidence that physicians immediately jump to prescribing medications before inquiring about basic needs such as access to proper nutrition [1]. In order to decrease the excessive obesity associated with SMI, medical students and health care professionals must alter their approach to patient care 


\section{Socioeconomic Factors}

"I used to have a family doctor, but he was so far away, and I wouldn't have bus fare, so I stopped going. At first I stopped taking my medication because I couldn't pay bus fare to go to the doctor." - Patient [1, p. 10].

Poverty makes it difficult to afford nutritional food, transportation for grocery shopping or medical appointments, and to take advantage of recreational opportunities $[1,15]$. Povertyrelated stress results in a greater risk for acquiring mental illness [16], while financial disparity significantly impacts food security and the ability to access a healthy diet $[17,18]$. Even though individuals with SMI can come from either a low or high socioeconomic status, a disproportionate number end up living in poverty as a result of their illness [1]. Poverty is associated with poor diets that are high in fat and low in fruits and vegetables, which are predictors of obesity and other negative health consequences [17]. Disadvantaged populations are also more likely to reside in obesogenic environments, or 'food deserts', that contain few supermarkets and places to exercise. Food supercenters, which are frequently located in areas of more advantaged populations, are often geographically and practically inaccessible to individuals with SMI [19].

Additionally, mortality from the most common diseases tends to be higher in areas characterized by low socioeconomic status [20]. Men in Canada's wealthiest $20 \%$ of neighbourhoods live more than four years longer than men in the poorest $20 \%$ of neighbourhoods, with the latter having a $28 \%$ higher mortality rate [15]. Many preventable diseases, such as adult-onset diabetes and heart disease, are more prevalent among Canadians living in poverty [15]. Cigarette smoking, the leading cause of preventable deaths in high-income countries, is also more prevalent in low-income populations and a significant comorbidity in people suffering from SMI [21]. Given these findings, it is essential that medical care professionals inquire about their patients' living situation and understand situational factors that may influence the physical health of patients with SMI. On a broader level, physicians can advocate for their patients by fighting for policy changes affecting food security in lower income areas.

\section{Behaviour and Lifestyle Factors}

Although poverty and the resulting limited ability to afford a nutritious diet create almost certain barriers to a healthy lifestyle, patients with SMI are significantly more likely to report poor exercise habits (e.g., walking infrequently), poor eating behaviours (often consuming fewer than two daily meals), and weight gain even after income has been accounted for [22]. Health care providers are also less likely to discuss eating habits or physical activity with patients with SMI, pointing to poor preventive care [22]. This absence of counselling leads to a lack of knowledge regarding what constitutes a healthy diet [23], and patients consuming foods higher in refined sugar, fat, and salt as a result [24].
Physical inactivity and poor diet greatly contribute to the development of obesity, hypertension, raised blood cholesterol/dyslipidemia, and high fasting blood sugar, all of which are risk factors for metabolic syndrome, a condition associated with cardiovascular disease, diabetes, and stroke [3]. People with SMI, who are approximately two to three times more likely to be overweight and to have diabetes, hypertension, or dyslipidemia, are therefore also at much greater risk for developing heart disease, diabetes, and stroke from metabolic syndrome $[4,25]$. People with SMI are also more likely to use substances such as alcohol and cannabis [26]. Prevalence of alcohol abuse is three to four times higher in patients with SMI $[27,28]$, and both alcohol and cannabis use is associated with a variety of adverse health outcomes including diabetes, hypertension, congestive heart failure, stroke, and dementia $[29,30]$. Individuals with SMI also report exceptionally high rates of cigarette smoking and tobacco dependence $[25,28,31]$. In individuals with SMI, international prevalence rates of smoking range from $58 \%$ to $88 \%$, up to three times higher than the general population [32]. The high rates of smoking not only increase mortality in individuals with SMI, but also result in higher prevalence of chronic respiratory diseases such as chronic bronchitis and asthma [13]. The high level of co-occurring substance use also has significant financial implications. Dependent individuals may choose to purchase tobacco or alcohol over food, leading to food insecurity regardless of whether there is enough reported income to purchase food. Moreover, this also impacts income available for transportation, which has more direct effects on how much social and physical activity these individuals engage in. The resulting lower rates of activity lead to decreased fitness, increased stress, social isolation, and ultimately even greater substance consumption.

\section{Health Care System Barriers and Poor Preventative Medicine}

"Doctors don't take you seriously when you have 'mental health' issues. I went to the doctor to get antibiotics for an infection and was told 'if you came here for pills, you've got another thing coming.' It turns out I had pneumonia." - Patient [1, p. 14].

In Canada, over $50 \%$ of people with SMI receive care from their primary physician $[33,34]$. However, lack of specialized knowledge regarding mental health issues by primary care physicians, pre-existing stigma, and poor communication when referring to psychiatrists can result in mismanagement of these patients [33]. Care of patients with SMI faces a double-edged sword: primary care physicians may not be comfortable or have the necessary skills to treat the health issues of patients with SMI, while psychiatrists may not believe that physical health is their domain to treat [34]. Additionally, physicians may not take complaints seriously from those suffering with SMI, who may, in addition to being stigmatized, experience difficulty communicating their symptoms to the physician [1]. Moreover, the fee-forservice billing model commonly used in Canada favours patients 
of low complexity that can be dealt with in a short time period, thereby putting patients with SMI at a significant disadvantage [1].

Fewer than $10 \%$ of people with a SMI received services such as vocational rehabilitation, day treatment, or case management [35] and patients with SMI experience higher emergency care use, fewer routine preventative check-ups, and increased risk of post-operative infections and complications [36]. They are also less likely to receive the standard of care for diabetic monitoring. There is some evidence that mortality increases by anywhere from $19 \%$ to $34 \%$ for patient with SMI following a myocardial infarction [36]. The disparities in standard of care extend beyond primary care - people with SMI encounter poor treatment in emergency rooms, unrealistic discharge, and poor follow-up post-hospitalization [1]. Such health care inconsistencies and limited access to preventative care for individuals with SMI significantly increase the risk of early death and speak to the need for health care professionals to maintain high standard of care irrespective of patient mental health status

\section{Health Care System Barriers and Poor Preventative Medicine}

"You know how everyone knows a street corner is dangerous, but nobody builds the crosswalk until somebody dies? Well, a lot of people have already died. And now we've got to act." - Health care professional [1, p. 19].

On average, individuals with mental illness are dying an astounding 25 years earlier than the general population - a rate that has yet to change over the past decade $[1,36]$. Often, this premature death is from preventable conditions such as cardiovascular disease. A complex interplay of factors related to mental illness, behaviour and lifestyle, poverty, and insufficient preventative care contribute to this disparity. Not only are many individuals with SMI not engaging in healthy lifestyle behaviours, but economic circumstances, such as poverty, prevent them from doing so. Individuals with SMI are thus "choice disabled" [37] in that they "might like to benefit from prevention but are unable to do so because they do not have the power to make and to act on prevention decisions" [37], a situation exacerbated by a health care system with billing practices that deter general practitioners from taking on complex patients with SMI.

Unfortunately, despite the recent call for action [1], the excess mortality/morbidity of individuals with SMI remains high. The establishment of advocacy groups to assist individuals with SMI, including the Canadian Mental Health Association (CMHA) and the Canadian Alliance on Mental Illness and Mental Health (CAMIMH), are great initial steps towards driving change on an individual, societal, and political level. Yet if our society and our health care system do not begin to reflect the changes necessary to better meet the needs of individuals with SMI, including more integrated mental and physical health care and reimbursement practices that reward complex care, such efforts will be futile.
Change must also begin with medical education, a place where future health care professionals and advocates are made. The time for moving forward in lowering the striking disparities in mortality rates in SMI is now, and it starts with greater recognition of this issue by medical students and other health professionals who are the future of health care.

\section{REFERENCES}

1. Andersson N. Prevention for those who have freedom of choice - or among the choicedisabled: confronting equity in the AIDS epidemic. AIDS Res Ther. 2006;3:23.

2. Callaghan RC, Khizar A. The incidence of cardiovascular morbidity among patients with bipolar disorder: a population-based longitudinal study in Ontario, Canada. J Affect Disorders. 2010;122(1-2):118-123.

3. Chang SC, Lu ML. Metabolic and cardiovascular adverse effects associated with treatment with antipsychotic drugs. J Clin Exp Med. 2012;4(2):103-107.

4. Colton CW, Manderscheid RW. Congruencies in increased mortality rates, years of potential life lost, and causes of death among public mental health clients in eight states. Prev Chronic Dis. 2006;3(2):1-14.

5. Conway KP, Compton W, Stinson FS, Grant BF. Lifetime comorbidity of DSMIV mood and anxiety disorders and specific drug use disorders: results from the National Epidemiologic Survey on Alcohol and Related Conditions. J Clin Psychiatry. 2006;67(2):247-57.

6. Corrigan P. How stigma interferes with mental health care. Am Psychol. 2004;59(7):614-625.

7. Cradock-O'Leary J, Young AS, Yano EM, Wang M, Lee ML. Use of general medical services by VA patients with psychiatric disorders. Psych Serv. 2002;53:874-878.

8. Curkendall SM, Mo J, Glasser DB, Rose Stang M, Jones JK. Cardiovascular disease in patients with schizophrenia in Saskatchewan, Canada. J Clin Psychiat. 2004;65(5):715- 720.

9. Dani JA, Harris RA. Nicotine addition and comorbidity with alcohol abuse and mental illness. Nat Neurosci. 2005;8(11):1465-70.

10. Davidson, KM, Kaplan BJ. Food intake and blood cholesterol levels of community-based adults with mood disorders. BMC Psych. 2012;12:10-18.

11. De Hert M, Correll CU, Cohen D. Physical illness in patients with severe mental disorders. I. Prevalence, impact of medications and disparities in health care. World Psychiatry. 2011;10:52-77.

12. De Hert M, Dobbelaere M, Sheridan EM, Choen D, Correll CU. Metabolic and endocrine adverse effects of second-generation antipsychotics in children and adolescents: a systematic review of randomized, placebo controlled trials and guidelines for clinical practice. Eur Psychiatry. 2011;26(3):144-58.

13. de Leon J, Diaz FJ. A meta-analysis of worldwide studies demonstrates an association between schizophrenia and tobacco smoking behaviors. Schizophr Res. 2005;76(2-3):135-157.

14. Drewnowski A, Specter SE. Poverty and obesity: The role of energy density and energy costs. Am J Clin Nutr. 2004;79(1):6-16.

15. Drewnowski A, Darmon N. Food choices and diet costs: an economic analy sis. J Nutr. 2005;135(4):900-904.

16. Fagiolini A, Goracci A. The effects of undertreated chronic medical illnesses in patients with severe mental disorders. J Clin Psychiatry. 2009;70:22-9.

17. Frye MA, Salloum IM. Bipolar disorder and comorbid alcoholism: prevalence rate and treatment considerations. Bipolar Disord. 2006;8:677-685.

18. Goldman LS. Medical illness in patients with schizophrenia. J Clin Psych. 1999;60:10-5.

19. Hayes RD, Chang CK, Fernandes AC, et al. Functional status and all-cause mortality in serious mental illness. PLoS ONE. 2012;7(9):e44613.

20. Hall W, Degenhardt L. Adverse health effects of non-medical cannabis use. Lancet. 2009;374:1383-1391.

21. Hennekens $\mathrm{CH}$, Hennekens AR, Hollar D, Casey DE. Schizophrenia and increased risks of cardiovascular disease. Am Heart J. 2005;150:1115-21.

22. Holt RIG, Peveler RC. Diabetes and cardiovascular risk in severe mental illness: a missed opportunity and challenge for the future. Pract Diab Int. 2010;27:79-84.

23. Kates N, Craven M, Albert JM, et al. Shared mental health care in Canada Ottawa, Ont: Canadian Psychiatric Association and College of Family Physicians of Canada; 2000.

24. Kilbourne AM, Morden NE, Austin K, et al. Excess heart-disease-related mortality in a national study of patients with mental disorders: identifying 
modifiable risk factors. Gen Hosp Psychiatr. 2009;31(6):444-63.

25. Kilbourne AM, Rofey DL, McCarthy JF, Post EP, Welsh D, Blow FC. Nutrition and exercise behavior among patients with bipolar disorder. Bipolar Disord. 2007; 9(5):443- Lovasi GS, Hutson MA, Guerra M, Neckerman KM. Built environments and obesity in disadvantaged populations. Epidemiol Rev. 2009;31:7-20.

26. Matsuoka A, Pitchot C, Saunders C, et al. 40 is too young to die. Toronto, Ont: Early- Onset Illness and Mortality Group; 2011.

27. Mikkonen J, Raphael D. Social determinants of health: the Canadian facts. Toronto: York University School of Health Policy and Management; 2010.

28. Morden NE, Mistler LA, Weeks WB, Bartels SJ. Health care for patients with serious mental illness; family medicine's role. J Am Board Fam Med. 2009;22(2):187-195.

29. O'Keefe JH, Bybee KA, Lavie CJ. Alcohol and cardiovascular health: the razorsharp double-edged sword. J Am Coll Cardiol. 2007;50(11):1009-1014.

30. Parks J, Svendsen D, Singer P et al (eds). Morbidity and mortality in people with serious mental illness. Alexandria: National Association of State Mental Health Program Directors (NASMHPD) Medical Directors Council; 2006.

31. Phelan M, Stradins L, Morrison S. Physical health of people with severe mental illness. BMJ. 2001;322:443-4.

32. Robson D, Gray R. Serious mental illness and physical health problems: a discussion paper. Int J Nurs Stud. 2007;44:457-466.

33. Santiago CD, Kaltman S, Miranda J. Poverty and mental health: how do low-income adults and children fare in psychotherapy? J Clin Psychiatry. 2013;69(2):115-26.

34. Sokal J, Messias E, Dickerson FB, et al. Comorbidity of medical illnesses among adults with serious mental illness who are receiving community psychiatric services. J Nerv Ment Dis. 2004;192:421-427.

35. Whitley E, Gunnell D, Dorling D, Smith GD. Ecological study of social fragmentation, poverty, and suicide. BMJ. 1999;319(7216):1034-7.

36. Ziedonis D, Hitsman B, Beckham JC, et al. Tobacco use and cessation in psychiatric disorders: National Institute of Mental Health report. Nicotine Tob Res. 2008;10(12):1691-1715.

Keywords: severe mental illness, mental disorders, premature mortality, morbidity, early death, comorbidity, prevention, primary care, psychiatry, health advocacy 